MAGDALENA CATTAN LAVIN

DEPARTAMENTO DE DISEÑO

FACULTAD DE ARQUITECTURA Y URBANISMO

UNIVERSIDAD DE CHILE

SANTIAGO, CHILE

MCATTAN@UCHILEFAU.CL

PHD CANDIDATE

EDINBURGH COLLEGE OF ART.

THE UNIVERSITY OF EDINBURGH
Cómo citar: Cattan, M. (2019).

Artesanía. Repensando "Lo Tradicional"

y la Relación Artesanía/Diseño.

RChD: creación y pensamiento, 4 (7), 1-4

Revista Chilena de Diseño

RChD: creación y pensamiento

Universidad de Chile

2019, 4(7)

http://rchd.uchile.cl

\section{Artesanía. Repensando "Lo Tradicional” y la Relación Artesanía/Diseño}

\author{
Crafts. Rethinking "The Traditional" \\ and the Craft / Design Relationship
}

La Artesanía, como práctica cultural, es un universo único, holístico y complejo donde múltiples dimensiones coexisten, desde el territorio hasta el mundo de los objetos, que son más que simples objetos; son artefactos significativos y representaciones materiales de una realidad singular (Walker, 2018; Mier y Terán, 2013). Pero, sobre todo, la Artesanía es una "manera de hacer" (Niedderer y Townsend, 2014; Adamson, 2007; Greenhalgh, 2002). Se parte desde la premisa que esta manera de hacer está intrínsecamente vinculada al trabajo con las manos; se desprende que la Artesanía tiene una conexión única con todos los sentidos humanos que genera un espacio de intimidad entre el creador y la pieza (Metcalf, 2007; Shiner: 2007).

El educador y folclorista chileno Fidel Sepúlveda consideraba a la Artesanía como el "mapa cognitivo que ilustra el vínculo y el diálogo entre el hombre y su entorno" (Sepúlveda, 2003). De manera similar, la antropóloga mexicana Marta Turok afirma en su texto seminal, Entender la Artesanía, que la riqueza y diversidad de una comunidad se puede ver en sus oficios al reconocer en ellos la interacción de los materiales provistos por el entorno físico, los procesos tecnológicos desarrollados por las personas, la organización de la producción, y sobre todo, la cosmovisión de los cultores (Turok, 1988).

El presente Dossier cuenta con seis artículos que ahondan en el ámbito de la Artesanía desde diversas perspectivas: como una práctica dinámica y creativa, cuyas fronteras están en constante reconfiguración, ampliándose y/o adaptándose a realidades y contextos; la observación de la práctica y sus atributos; el relevo del conocimiento tácito de los cultores y discutiendo sobre su relación con los diseñadores. Estos artículos se complementan con cuatro entregas en la sección "Otros Contenidos", donde se indaga sobre las instancias de extensión para las artesanías en el ámbito nacional e internacional, que cierra con una reflexión en torno a prácticas éticas de colaboración. Un tema de importante relevancia para este número, es la discusión sobre la relación entre Artesanía y Diseño, no solo respecto al ámbito de producción material, sino que en términos éticos y discursivos (de mediación), particularmente en contextos de comunidades culturalmente significativas.

La actual Política Nacional de Artesanía 2017-2022 menciona que las acciones de asociación entre artesanos y diseñadores se han evaluado positivamente en general, en la medida en que estos últimos han desempeñado un papel de facilitador para que los artesanos ingresen en nuevos mercados y trabajen para mejorar la apariencia final de los objetos artesanales. Sin embargo, cuando se trata de colaboraciones creativas, los artesanos han expresado su preocupación al indicar que no se trata de colaboraciones balanceadas, sino que, principalmente de asistencia productiva (CNCA, 2017). Sucede que debido a la vocación disciplinar, el Diseño está altamente seducido por la forma, los objetos y los procesos de producción, la primera acción 
es la de intervención, directamente orientada a los objetos, que integra herramientas o desarrolla procesos más eficientes. Esta forma de actuar también responde al enfoque estándar de Diseño como "solucionador de problemas". En este sentido, algunas posturas críticas se han desarrollado como la del teórico de Diseño Tony Fry (2011), quien aborda esta discusión argumentando que en lugar de ser una actividad de "resolución de problemas", el Diseño ha sistemáticamente creado más problemas a partir de una idea preconcebida de progreso y mejora. Una contrapropuesta a este enfoque, es pensar el Diseño como un "definidor de problemas", lo que implica desarrollar una investigación crítica que explique y cuestione las estructuras de pensamiento que organizan las sociedades modernas, es decir, la colonización epistemológica y el eurocentrismo (Fry, 2011). En otras palabras, es un llamado al desarrollo de un enfoque de Diseño decolonial, que reconoce la producción de conocimiento como una actividad relacional, situada en contextos que no son universales sino particulares que privilegian y alaban las diferencias ontológicas de las personas (Escobar, 2018; Schultz et al. 2018).

Si bien los enfoques "centrado en el objeto" y de "resolución de problemas" han contribuido en ciertos aspectos al sector artesanal, se podría argumentar que también han sido insuficientes a la hora de validar estas prácticas como conocimiento relevante y hacerlas sostenibles en el tiempo. Según Fry, esto sucede porque, en la práctica convencional, los diseñadores a menudo desarrollan respuestas preestablecidas que se limitan a lo que se espera que se resuelva y, en la intención de empoderar y mejorar las vidas de las comunidades vulnerables -por ejemplo económicamente-, las acciones de Diseño centrada en normas estandarizadas tienden a perpetuar la percepción de nuestra disciplina como un agente de neocolonialismo epistémico en la medida en que opera -a pesar de las genuinas buenas intenciones- desde una posición universalista que sugiere que nuestros conocimientos son más apropiados que los producidos por la comunidad local (Escobar, 2018; Kalantidou y Fry 2014; DeNicola y Wilkinson-Weber, 2016).

En este sentido, el surgimiento de nuevas posturas críticas en nuestro ámbito disciplinar propician un espacio para la reflexión y quizás una reconfiguración del rol que ha tenido el Diseño en la Artesanía donde cabe preguntarse: ¿Por qué intervendré y en qué nivel? ¿Es necesario? ¿Cuál es el propósito de mi intervención? ¿Cuáles serían los impactos para el artesano, la comunidad y el medio ambiente?

En esta línea, el artículo de Diego Miér y Terán y Kythzia Barrera, directores del colectivo Innovando la Tradición y Colectivo $1050^{\circ}$, proponen una visión de trabajo colaborativo entre artesanos y diseñadores que se centra justamente en una mirada crítica de los enfoques tradicionales positivistas del Diseño. En su artículo, comparten su visión y las acciones desarrolladas en sus quince años de experiencia con comunidades alfareras rurales de Oaxaca, las cuales han emergido desde a los contextos locales.

El trabajo de Raquel Noronha y Gloriana Solís, investigadoras de NIDA, núcleo de investigaciones en Innovación, Diseño y Antropología, presenta una reflexión metodológica basada en las prácticas de correspondencia in-situ del antropólogo Tim Ingold como estrategia para acercarse a un trabajo colaborativo efectivo y balanceado entre artesanos indígenas y diseñadores. A través de un caso de estudio situado en Costa Rica y Brasil, las autoras discuten cómo estas prácticas de correspondencia invitan a deconstruir el 
enfoque tradicional de Diseño moderno -centrado en ideas preconcebidas de progreso-, lo que da paso a la intuición y experimentación/acción en terreno guiado por el saber-hacer de los mismos cultores.

Para cerrar esta línea temática, se presenta el artículo de Stuart Walker, Louise Mullagh y Martyn Evans, investigadores de las universidades de Lancaster y Manchester Metropolitan, que aborda los resultados del proyecto de investigación "Living Design: The Effective Use of Design for Sustainability in Small Maker Enterprises", que es un modelo de trabajo centrado en un rol activo del diseñador como ente facilitador para la sustentabilidad de pequeñas pymes artesanales de gran arraigo territorial en el Reino Unido.

Aún en la línea de colaboración entre Artesanía y Diseño, cabe preguntarse sobre la constante transformación de realidades y contextos, ¿qué narrativa prevalece hoy en torno a la práctica tradicional? ¿Qué es lo tradicional hoy? ¿Y qué ocurre cuando llegamos a las nuevas fronteras del quehacer artesanal? ¿Cómo dialoga lo análogo con lo digital? ¿Cuál es el rol del Diseño en ello? El artículo de Pablo Igu, maker e investigador independiente, presenta una amplia reflexión en torno a la relación entre Artesanía y Diseño, donde indaga en los atributos de ambas prácticas en tanto relato, taller, función y belleza, esta es la base de conocimiento para abordar una noción de "nuevas artesanías" donde confluyen no solo las herramientas digitales -como impresión 3D y fabricación digital-, y análogas -como el taller de carpintería-, sino que enfoques metodológicos de trabajo y discurso.

Luego, el artículo de la diseñadora Sofía Guridi indaga de lleno en los bordes de la Artesanía y las nuevas tecnologías, adentrándose en el ámbito de computational craft, donde las herramientas análoga y digital se combinan para potenciar atributos de la obra. En particular, el artículo revisa el trabajo en curso de la autora, donde experimenta al integrar tecnologías de e-textile a tradicionales arpilleras para potenciar el carácter narrativo de su mensaje. Una segunda línea temática que cierra la sección de artículos del presente dossier aborda la discusión sobre el concepto de Artesanía en relación al quehacer y la práctica. Javiera Naranjo, socióloga y cofundadora de la organización Oficios Varios, expone una discusión crítica sobre de las categorías de Artesanía y Artes Populares, donde dilucida cómo estas denominaciones han situado estas prácticas unas por sobre otras, lo que llega a reducir la significación cultural y valoración de su producción. En este contexto, propone un vuelco epistémico al proponer el uso del concepto de oficios que lejos de simplificar, abre espacio a una compresión multidimensional del quehacer con las manos.

La sección Otros Contenidos se inicia con un texto por la artista visual Nury González, actual directora del Museo de Arte Popular Tomás Lago, el cual se centra en la ruta recorrida hacia la prestigiosa Biennale Révélation, organizada por la Asociación de Artesanos de Francia Ateliers d'Art, donde creadores chilenos, entre ellos varios artesanos tradicionales, han presentado su trabajo en los años 2015, 2017 (Chile como país de honor) y 2019. El texto comienza con una interesante contextualización histórica que sitúa la actual puesta en valor que se le da a los oficios manuales en Francia.

Tania Salazar Maestri, que sigue en el ámbito de la extensión, revisa el concepto de Artesanía desde la institucionalidad nacional e internacional, para luego realizar una reflexión sobre las instancias de apoyo en Chile, donde la 
comercialización del objeto final tiende a ser el objetivo. A partir de ello, propone mirar más allá de las ferias tradicionales e invita a reflexionar sobre la necesidad de potenciar nuevos espacios de circulación cultural, donde pone énfasis en la valoración de los cultores, su relato y territorio.

El breve ensayo de Roxana Amarilla, directora del Mercado de Artesanías Tradicionales de Argentina y vicepresidenta del wCC, plantea valiosas preguntas en torno al ámbito ético de la colaboración entre artesanos y diseñadores, indaga en los diversos enfoques y modelos de "buenas prácticas" que se han desarrollado en nuestra región.

A modo de cierre, presentamos una entrevista realizada a Guillermo Parada, socio fundador del estudio gt2p (Great Thing to People), donde se refirió a los inicios del estudio y cómo a través de la experimentación con materiales y procesos se acercaron al ámbito de digital crafting o artesanía digital -donde se combinan herramientas de fabricación análogas y digitales- la cual se ha transformado en el aspecto más reconocible de su propuesta. Finalmente, aborda el tema de la difusión internacional y su relevancia para potenciar el Diseño chileno. 